\title{
Lateral hypothalamic electrode implantation disrupts lithium-chloride-based generalized aversion to sodium chloride by enhancing sodium appetite
}

\author{
RUSSELL L. MARTIN \\ Monash University, Clayton, Victoria, Australia \\ and \\ GEOFFREY R. HAMMOND \\ University of Western Australia, Nedlands, Western Australia, Australia
}

\begin{abstract}
Bilateral implantation of bipolar stimulating electrodes in the lateral hypothalamic area was found to be sufficient itself to disrupt a generalized aversion to $\mathrm{NaCl}$ in $\mathrm{LiCl}$-poisoned rats. The primary aversion to $\mathrm{LiCl}$ remained undisturbed. This finding was confirmed in a second experiment, which also showed that electrical stimulation did not have any additional disruptive effect upon the generalized aversion. The only additional effect of stimulation was a reduction in intensity of the primary aversion. The impairment of the generalized aversion therefore appears to be an artifact of tissue damage resulting from electrode implantation. In a third experiment, it was shown that electrode implantation in the lateral hypothalamic area increases sodium preference measured in a two-bottle preference test. It is suggested that enhanced sodium appetite in implanted animals is the mechanism by which the generalized aversion to $\mathrm{NaCl}$ is disrupted after $\mathrm{LiCl}$ poisoning; such animals consume $\mathrm{NaCl}$ freely, but their intake of $\mathrm{LiCl}$ is limited due to the rapid onset of toxic reactions following consumption. The differential effect on consumption of the two substances is a result of their differential toxicity.
\end{abstract}

On experiencing illness subsequent to ingestion of a particular food, most animals will learn to avoid the food on future encounters (Richter, 1953). The neural mechanisms underlying this phenomenon have been the subject of several recent studies, and investigations are currently at the stage of identifying the gross neural structures involved (for a review, see Gaston, 1978). One of the few structures that have been consistently implicated is the lateral hypothalamus (LH).

Three studies have suggested that electrical stimulation of the LH interferes with taste aversion learning (Balagura, Ralph, \& Gold, 1972; Lett \& Harley, 1974; Ralph \& Balagura, 1974). Balagura et al. (1972) investigated the effects of continuous low-level stimulation of the $\mathrm{LH}$ of rats when applied immediately following consumption of a toxic amount of lithium chloride $(\mathrm{LiCl})$. They tested for acquisition of an aversion several days later by offering a solution of sodium chloride $(\mathrm{NaCl})$. Equi-

\footnotetext{
The research reported here formed part of an honors degree in psychology completed by the senior author at the University of Western Australia. Reprint requests may be addressed to the senior author at: Department of Psychology, Monash University, Clayton, Victoria 3168, Australia.
}

molor solutions of $\mathrm{LiCl}$ and $\mathrm{NaCl}$ are particularly difficult for a rat to discriminate, so normal rats readily generalize a learned aversion from one to the other (Nachman, 1963). Balagura et al. (1972) found that stimulated animals displayed less aversion (as shown by greater consumption of $\mathrm{NaCl}$ ) than did unstimulated controls. In a follow-up study, Ralph and Balagura (1974) again stimulated rats in the LH immediately after consumption of a toxic amount of $\mathrm{LiCl}$. In their Experiments 1 and 2, they tested for acquisition of a primary aversion to $\mathrm{LiCl}$ as well as for acquisition of a generalized aversion to $\mathrm{NaCl}$. They found that, as before, the generalized aversion to $\mathrm{NaCl}$ in stimulated animals was attenuated, but that, surprisingly, the primary aversion to $\mathrm{LiCl}$ was unaffected. In a third experiment, they showed that the disruption of the generalized aversion to $\mathrm{NaCl}$ by LH stimulation was independent of whether the stimulation was rewarding or not. Because of this, and because the primary aversion was unaffected by stimulation, Ralph and Balagura (1974) concluded that the disruptive effect of the stimulation was not a result of attenuation of the aversive qualities of $\mathrm{LiCl}$ induced illness. Such an interpretation had been suggested by Lett and Harley (1974) on the basis of their observation that rewarding LH stimulation disrupted 
acquisition of a LiCl-based aversion to decaffeinated coffee when administered following induction of illness but not when administered in the interval between consumption of the coffee and illness. Ralph and Balagura (1974) concluded that the asymmetrical effect of LH stimulation on the primary and generalized aversion was a result of stimulation disrupting some "generalization mechanism" or enhancing the animals' taste sensitivity such that they could discriminate equimolar solutions of $\mathrm{LiCl}$ and $\mathrm{NaCl}$.

\section{EXPERIMENT 1}

The studies by Balagura et al. (1972), Ralph and Balagura (1974) and Lett and Harley (1974) possessed a common methodological deficiency. Although the control animals in all three studies underwent some form of control surgery, none was implanted with electrodes comparable to those used on the experimental animals. (Three of the control animals used by Lett and Harley, 1974, had been previously implanted with an otherwise unspecified midbrain electrode). In none of these studies was tissue damage caused by electrode implantation controlled for. Therefore, the effects observed by these authors cannot be attributed positively to stimulation of the LH.

The possibility that the effects observed by Balagura et al. (1972) and Ralph and Balagura (1974) were due to implantation of electrodes in the $\mathrm{LH}$ was investigated in this experiment.

\section{Method}

Subjects. The subjects were 25 experimentally naive male rats, ranging in weight from 250 to $300 \mathrm{~g}$, from the Wistar-derived colony maintained at the University of Western Australia.

Each rat was individually caged in an animal housing room maintained at $24^{\circ} \mathrm{C}$ and $60 \%$ humidity. Lighting was turned on at 7:00 a.m. and turned off at 7:00 p.m. every day. All rats had access to a diet of rat cubes and fluids, available from graduated drinking tubes.

Each rat was allocated nonsystematically to an experimental group of 10 animals (Group E) or to one of three control groups of 5 animals each (Groups $\mathrm{Cl}, \mathrm{C2}$, and $\mathrm{C} 3$ ).

Surgical procedure. All animals were anesthetized by intraperitoneal (ip) injection of $2 \mathrm{ml} / \mathrm{kg}$ Pentathesin and then placed in the stereotaxic apparatus. For animals in Group E, a longitudinal incision was made and the surface of the skull was exposed. The muscles on either side of the skull were retracted to expose the dorsolateral surfaces, and a .5-mm hole was drilled through both dorsolateral flexures, entering dorsally about $1 \mathrm{~mm}$ anterior to bregma. A $200-\mu \mathrm{m}$ stainless steel wire was threaded through both holes, and the ends were twisted together in a loop above the midline. The wire loop served as an anchor for dental acrylic that was used to secure the electrodes in position (Draper \& Venator, 1972). Two 2.5-mm holes were drilled through the dorsal surface of the skull to allow the passage of electrodes.

Two electrodes, each constructed of two twisted strands of 250$\mu \mathrm{m}$ Teflon-coated tungsten, were lowered into the brain of each experimental animal. The electrode tips were aimed at the $\mathrm{LH}$. Two coordinate systems were used to locate the electrodes. First, with bregma adjusted to be $1 \mathrm{~mm}$ superior to lambda, the co- ordinates used were: $1.5 \mathrm{~mm}$ posterior to bregma, $8.6 \mathrm{~mm}$ inferior to bregma, and $1.6 \mathrm{~mm}$ either side of the midline. Second, with the upper incisor bar adjusted to be $5 \mathrm{~mm}$ superior to the intra-aural bars, the coordinates used were: $1.4 \mathrm{~mm}$ posterior to bregma, $8.4 \mathrm{~mm}$ inferior to the dura, and $1.6 \mathrm{~mm}$ either side of the midline. The first five animals were implanted using the first set of coordinates; the next five were implanted using the second set, after it was realized that these were the coordinates used by Ralph and Balagura (1974). The electrodes were then cemented in position.

Animals in Groups $\mathbf{C 1}, \mathbf{C 2}$, and $\mathrm{C3}_{3}$ were treated identically except that no stainless steel wires were attached to their skulls (although the holes were drilled) and no electrodes were lowered into their brains (although again the holes were drilled).

All animals were given a .1-ml intramuscular injection of penicillin, and their scalp wound was sutured. They were placed in a warm recovery tray for a few hours and then returned to their cages.

Behavioral procedure. All animals were allowed 10 days to recover from surgery. On Days 11-15, all animals were placed on a fluid-deprivation schedule, with water available for $1 \mathrm{~h}$ from 10:00 a.m. On Day 16, animals in Groups $E$ and $C 1$ were offered a $.18 \mathrm{M} \mathrm{LiCl}$ solution and, after consumption of $3 \mathrm{ml}$, were given a $.6-\mathrm{ml}$ supplement of $3 \mathrm{M} \mathrm{LiCl}$ ip. Animals in Groups $\mathrm{C2}$ and $\mathrm{C} 3$ were offered tap water and, after consumption of $3 \mathrm{ml}$, were given $.6 \mathrm{ml}$ of isotonic saline ip. On Day 20, animals in Groups E, C1, and $\mathrm{C2}$ were offered $.18 \mathrm{M} \mathrm{LiCl}$ and animals in Group C3 were offered tap water. Intakes were recorded after 15, 60 , and $90 \mathrm{~min}$. On Days 24,28 , and 32 , the animals in all groups were offered $.18 \mathrm{M} \mathrm{NaCl}$, and intakes were recorded after 15,60 , and $90 \mathrm{~min}$. On the intervening days, all animals were returned to the restricted water schedule used on Days 11-15.

Histological procedure. All animals in Group E were anesthetized deeply with an overdose of Pentathesin. They were perfused through the heart with normal saline, followed by $10 \%$ Formalin in normal saline. Brains were removed, frozen, and then sectioned at $40-\mu \mathrm{m}$ intervals through the region of the hypothalamus. Alternate sections were mounted and stained with cresyl violet.

Electrode placements in each animal were determined by tracing tissue damage through consecutive sections, and coordinates describing the anterior-posterior placements of electrodes were obtained using the atlas of Pellegrino, Pellegrino, and Cushman (1979).

\section{Results and Discussion}

Of the 25 animals, 23 survived the experiment: 9 in Group E, 4 in Group C1, and 5 in each of Groups C2 and $\mathbf{C 3}$.

Histological. Electrodes were found to be well placed laterally and dorsoventrally in all implanted animals. However, although both sets of coordinates used to direct electrode implantation were expected to locate electrodes in a similar anterior-posterior placement, histological examinations revealed that this was not the case. The five animals implanted using the first set of coordinates were found to have electrodes placed more anterior than those in the four surviving animals implanted using the second set. The anterior-posterior coordinates describing electrode placements ranged from .8 to $1.4 \mathrm{~mm}$ posterior to bregma and from 1.6 to $2.6 \mathrm{~mm}$ posterior to bregma for the two sets, respectively. As the LH extends from $.8 \mathrm{~mm}$ anterior to bregma to $1.6 \mathrm{~mm}$ posterior to bregma, the first set of coordinates located electrodes in the $\mathrm{LH}$ while the second located 
electrodes posterior to it. For further analysis, Group E was therefore subdivided into two groups. Group E1 was made up of those animals with electrodes located in the LH, and Group E2 was made up of those with electrodes located posterior to it.

Behavioral. The mean $\mathrm{LiCl}$ intakes by Groups $\mathrm{E} 1$, E2, C1, and C2 on Postsurgical Day 20 after 15, 60, and $90 \mathrm{~min}$ of $\mathrm{LiCl}$ availability are shown in Figure 1. The mean intakes by Groups E1, E2, and C1 were each less than the mean intake by Group C2. Intake at $90 \mathrm{~min}$ was used to analyze between-groups differences. Analysis of variance of these data yielded a significant overall $F[F(3,14)=16.40, p<$ .05]. Using Fisher's method of multiple comparisons (Lindman, 1974), the mean intakes by Groups E1, $\mathrm{E} 2$, and $\mathrm{Cl}$ were each compared with the mean intake by Group C2. Each comparison was significant $[F s(1,4)=18.24,33.32$, and 42.40 , respectively, ps $<$ .05], indicating that Groups E1, E2, and C1 each drank significantly less $\mathrm{LiCl}$ than Group C2. Group $\mathrm{C} 2$ had had no previous experience with $\mathrm{LiCl}$, whereas Groups E1, E2, and $\mathrm{C1}$ all experienced $\mathrm{LiCl}$ poisoning 4 days earlier. Thus, Groups E1, E2, and $\mathrm{Cl}$ all displayed a significant aversion to $\mathrm{LiCl}$.

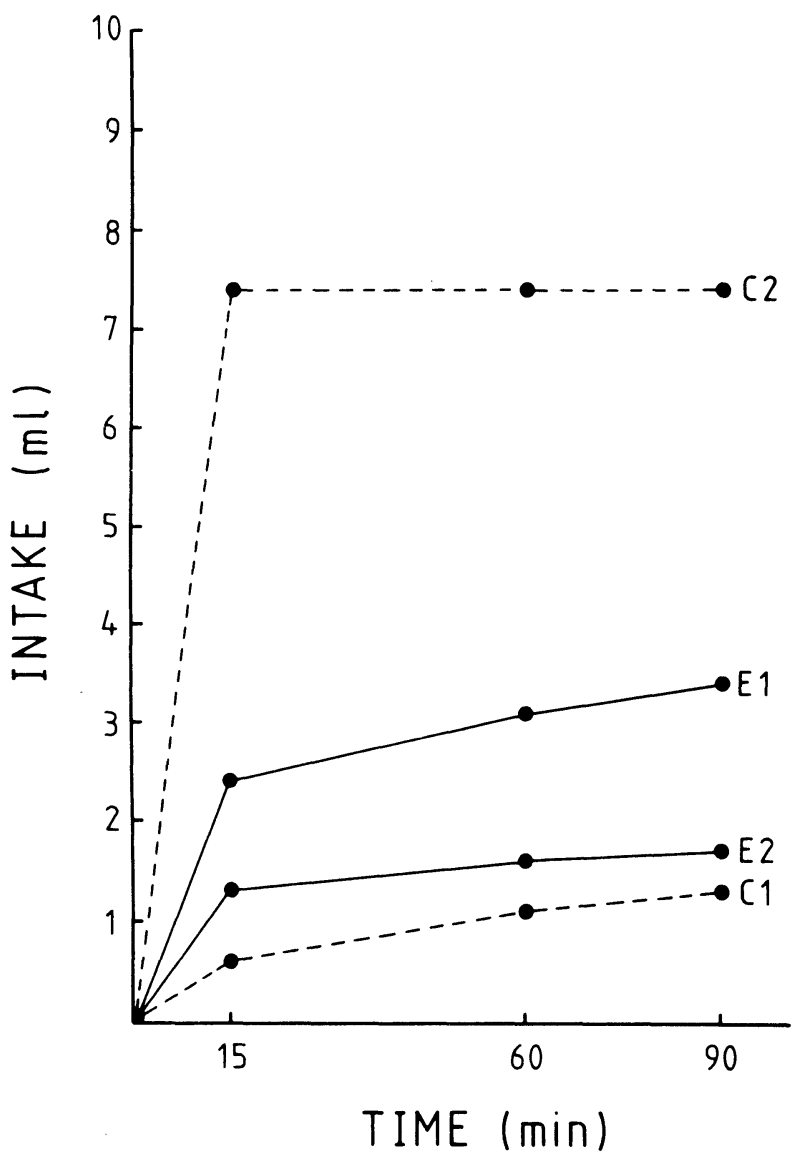

Figure 1. Mean LiCl intake by Groups E1, E2, C1, and C2 after 15,60 , and 90 min of fluid availability on Day 20.

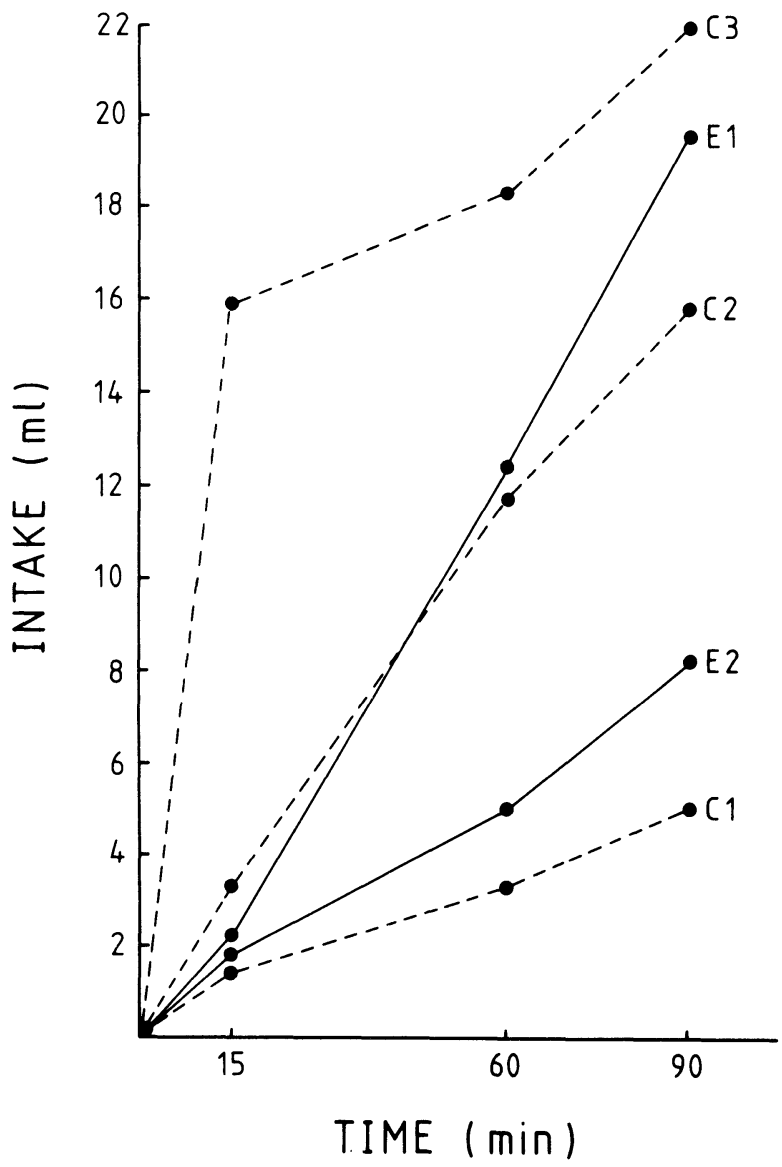

Figure 2. Mean $\mathrm{NaCl}$ intake by all groups after 15, 60, and 90 min of fluid availability on Day 24.

The mean $\mathrm{NaCl}$ intakes by Groups $\mathrm{E} 1, \mathrm{E} 2, \mathrm{C1}, \mathrm{C} 2$, and C3 on Postsurgical Day 24 after 15, 60, and 90 min of $\mathrm{NaCl}$ availability are shown in Figure 2. The mean intakes by Groups E1 and C2 were both similar to the mean intake by Group C3. The mean intakes by Groups E2 and $\mathrm{C} 1$ were both much less. Intake at $90 \mathrm{~min}$ was again used to analyze betweengroups differences, and analysis of variance of these data also yielded a significant overall $F[F(4,18)$ $=9.62, \mathrm{p}<.05]$. The mean intakes by Groups E1, $\mathrm{E} 2, \mathrm{C1}$, and $\mathrm{C2}$ were each compared with the mean intake by Group C3. Comparisons between Groups E2 and $\mathrm{C} 3$ and Groups $\mathrm{C} 1$ and $\mathrm{C3}$ were significant $[\mathrm{Fs}(1,18)=15.83$, and 27.11 , respectively, ps $<.05$ ], indicating that Groups E2 and $\mathrm{C1}$ both drank significantly less $\mathrm{NaCl}$ than Group C3. Group $\mathrm{C} 3$ had had no previous experience with $\mathrm{LiCl}$, while Groups $\mathrm{E} 2$ and $\mathrm{C} 1$ both experienced $\mathrm{LiCl}$ poisoning on two previous occasions. Thus, Groups $\mathrm{E} 2$ and $\mathrm{C} 1$ both displayed a significant generalized aversion to $\mathrm{NaCl}$ as well as the primary aversion to $\mathrm{LiCl}$ shown on Day 20. In contrast, comparisons between Groups E1 and C3 and Groups C2 and C3 were not significant, indicating that Groups E1 and 
C2 did not drink significantly less $\mathrm{NaCl}$ did than Group C3. Group $\mathrm{E} 1$ had experienced $\mathrm{LiCl}$ on two previous occasions, but did not display a significant generalized aversion to $\mathrm{NaCl}$ despite the fact that it had shown a primary aversion to $\mathrm{LiCl}$ on Day 20. Group $\mathrm{C} 2$ had experienced $\mathrm{LiCl}$ poisoning on one previous occasion, but did not display a significant generalized aversion to $\mathrm{NaCl}$. This was to be expected because, on this one occasion (Day 20), the animals in this group were offered $\mathrm{LiCl}$ but did not receive any supplementary injections.

The mean $\mathrm{NaCl}$ intakes by each of the five groups on postsurgical days 28 and 32 after 15,60 , and 90 min of $\mathrm{NaCl}$ availability are shown in Figures 3 and 4. On Day 28, the mean $\mathrm{NaCl}$ intakes by Groups $\mathrm{E} 1$ and $\mathrm{C} 2$ were both similar to the mean intake by Group C3. On this occasion, the mean intakes by Groups E2 and C1 were only slightly less. By Day 32, the mean intakes by all groups were similar except for that by Group E1, which was slightly greater.

Intake at $90 \mathrm{~min}$ was again used to analyze betweengroups differences. The mean intakes by Groups E1, $\mathrm{E} 2, \mathrm{C} 1$, and $\mathrm{C2}$ on each day were each compared with the corresponding mean intake by Group C3. Despite the trend for Groups E2 and C1 on Day 28,

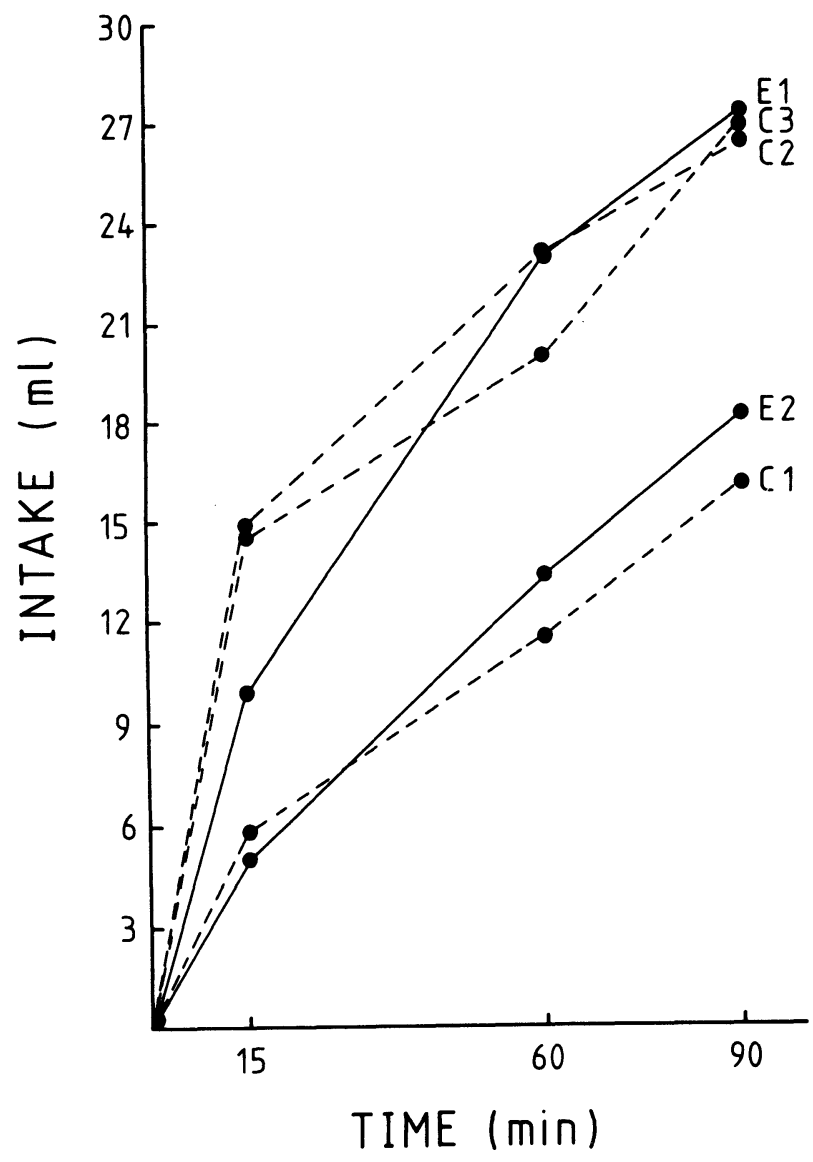

Figure 3. Mean $\mathrm{NaCl}$ intake by all groups after 15, 60, and 90 min of fluid availability on Day 28.

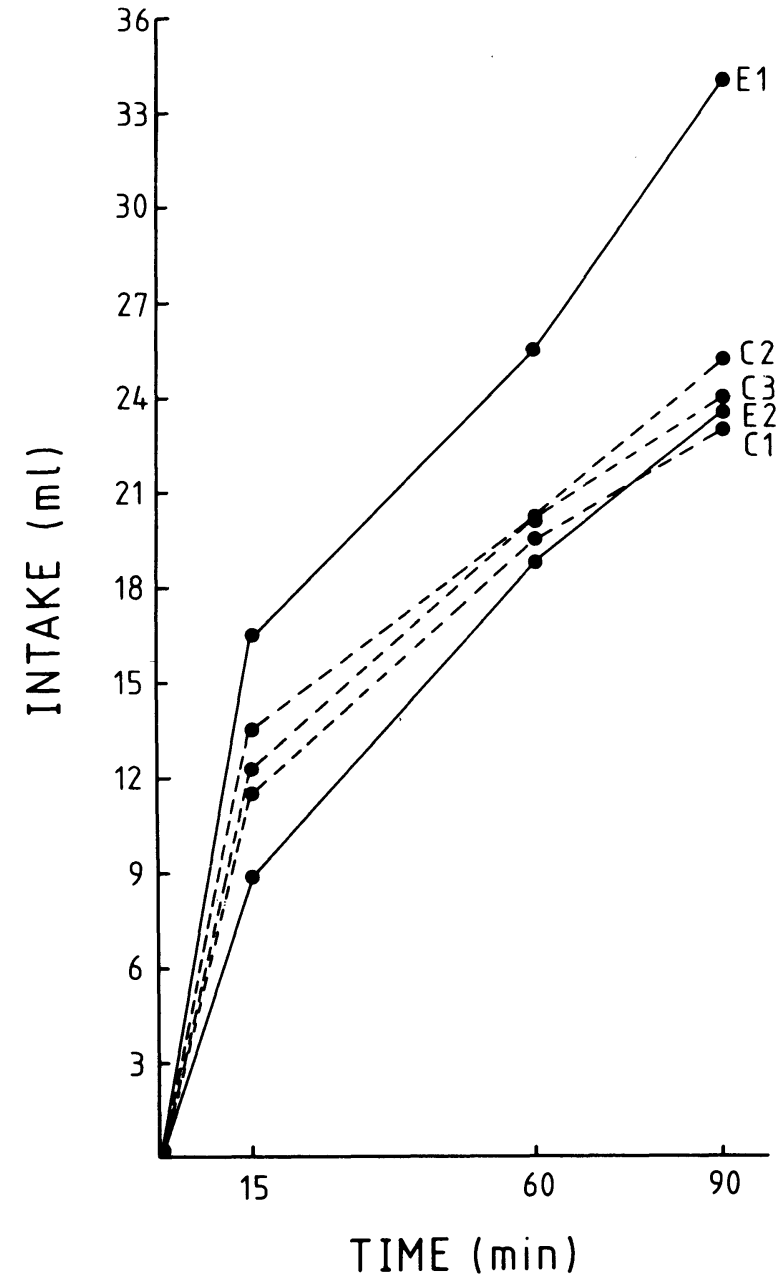

Figure 4. Mean $\mathrm{NaCl}$ intake by all groups after 15, 60, and 90 min of fluid availability on Day 32.

no group showed significantly lower intake than Group C3 on either day. The greater intake by Group E1 on Day 32 was not significant. These results show that the generalized aversion to $\mathrm{NaCl}$ displayed by Groups E2 and C1 on Day 24 had extinguished by Day 28.

Although the experimental animals in this study received no electrical stimulation, these results display the same pattern as those reported by Ralph and Balagura (1974). The control for tissue damage resulting from electrode implantation (C1) displayed a primary aversion to $\mathrm{LiCl}$ and a generalized aversion to $\mathrm{NaCl}$ on the first offer. By the second offer of $\mathrm{NaCl}$, this generalized aversion had extinguished. In contrast, the experimental group with electrodes implanted in the LH (E1) displayed a primary aversion to $\mathrm{LiCl}$ but did not generalize this aversion to $\mathrm{NaCl}$. The experimental group with electrodes implanted posterior to the LH (E2) behaved similarly to Group $\mathrm{C1}$, indicating that this effect is not associated with electrode implantation in any region of the 
brain. The only notable difference between the results of this experiment and those reported by Ralph and Balagura (1974) is the amount of $\mathrm{NaCl}$ consumed by the experimental animals. On the first offer of $\mathrm{NaCl}$, the mean intake by Group E1 $(19.5 \mathrm{ml})$ was less than that by Ralph and Balagura's (1974) stimulated animals (about $28.5 \mathrm{ml}$ ). Ralph and Balagura (1974) did not report individual data or any measure of variance, but it appears that their animals drank more than did our Group E1. This difference may have been caused by some procedural difference between the studies. The possibility that it was caused by either of two specific procedural differences was investigated in Experiment 2.

\section{EXPERIMENT 2}

Experiment 2 was run to assess the reliability of the finding of the first experiment and to examine the effect of two procedural differences between that experiment and those reported by Ralph and Balagura (1974). One obvious procedural difference between Experiment 1 and the study by Ralph and Balagura (1974) was that the experimental animals in Experiment 1 were not stimulated. It is possible that the effects of electrode implantation and stimulation of the LH are additive. Accordingly, a group of stimulated animals was included in this experiment. A second procedural difference was that, while the animals in Experiment 1 were allowed access to water for $1 \mathrm{~h}$ on each of the days intervening between taste aversion training and testing days, those in the study by Ralph and Balagura (1974) were allowed access for $6 \mathrm{~h}$ each day. To eliminate this difference, access to water in this experiment was restricted to $6 \mathrm{~h}$ each day.

Apart from these two changes, the design of this experiment was identical to that of Experiment 1.

\section{Method}

Subjects. The subjects were 29 experimentally naive male rats, ranging in weight from 250 to $300 \mathrm{~g}$, supplied from the Wistarderived colony maintained at the University of Western Australia. All rats were housed under conditions identical to those in Experiment 1.

Each rat was allocated nonsystematically to one of two experimental groups of five and nine animals each (Groups E1 and E2, respectively) or one of three control groups of five animals each (Groups C1, C2, and C3).

Surgical Procedure. Animals in Groups E1 and E2 were implanted with electrodes aimed at the $\mathrm{LH}$, and animals in Groups $\mathrm{C1}, \mathrm{C2}$, and C3 underwent control surgery as described in the Method section of Experiment 1. When implanted, electrodes were located with the set of coordinates that had given effective $\mathrm{LH}$ placements in Experiment 1.

Behavioral procedure. The general procedure was identical to Experiment 1 except that animals in Group E2 received electrical stimulation in the $\mathrm{LH}$ subsequent to $\mathrm{LiCl}$ poisoning and all animals were of fered $\mathrm{NaCl}$ on only one occasion.

All animals were allowed 10 days to recover from surgery. On Days 11-15, they were placed on a fluid-deprivation schedule with water available for $6 \mathrm{~h}$ from 10:00 a.m. On Day 16, the animals in Groups E1, E2, and $\mathrm{C} 1$ were offered a $.18 \mathrm{M} \mathrm{LiCl}$ solution and, after consumption of $1.5 \mathrm{ml}$ (less than in Experiment 1 to compensate for the expected decrease in motivation to consume fluids), were given a .6-ml supplement of $3 \mathrm{M} \mathrm{LiCl}$ ip. Animals in Groups $\mathrm{C} 2$ and $\mathrm{C} 3$ were offered tap water and, after consumption of $1.5 \mathrm{ml}$, were given $.6 \mathrm{ml}$ of isotonic saline ip. Immediately following injection, the animals in Group E2 were stimulated continuously for $6 \mathrm{~h}$ through the hypothalamic electrodes. Stimulation consisted of constant-voltage negative-going monophasic pulses (2-msec duration) generated at a rate of 60 pps by a Grass SD9 stimulator. Stimulus voltage was adjusted for each animal to $75 \%$ of the level that caused overt behavior. The amplitudes used were $1.4,1.8$, and $2.0 \mathrm{~V}$. On Day 20, the animals in Groups E1, $\mathrm{E} 2, \mathrm{C} 1$, and $\mathrm{C} 2$ were offered $.18 \mathrm{M} \mathrm{LiCl}$ and the animals in Group C3 were offered tap water. Intakes were recorded after 15 , 60 , and $90 \mathrm{~min}$. On Day 24 , intake of $.18 \mathrm{M} \mathrm{NaCl}$ by all animals was recorded after 15,60 , and $90 \mathrm{~min}$. On intervening days, the restricted water schedule applied.

Histological procedure. Animals in Groups E1 and E2 were anesthetized deeply with an overdose of Pentathesin. Sections through the hypothalamus were prepared, and electrode placements were determined as described in the Method section of Experiment 1.

\section{Results and Discussion}

Of the 29 animals, all but four survived the experiment. Nonsurviving animals had been allocated to Group E2.

Histological. All animals in Group E1 were found to have electrodes well placed in the LH. Placements in the animals of Group E2 were inconsistent. In three animals, electrodes were well placed in the LH. In one animal, one electrode was placed in the $\mathrm{LH}$ but the other was not, and in another, electrode placement was symmetrical but superior to the LH (electrodes did not penetrate below the thalamus). A substantial amount of infection was also present in this animal. Only results from the three animals with appropriate placements were analyzed.

Behavioral. The mean $\mathrm{LiCl}$ intakes by Groups $\mathrm{E} 1$, $\mathrm{E} 2, \mathrm{C1}$, and $\mathrm{C2}$ after 15,60 , and $90 \mathrm{~min}$ of $\mathrm{LiCl}$ availability are shown in Figure 5 . The mean intakes by Groups E1, E2, and $\mathrm{Cl}$ were each less than the mean intake by Group C2. Intake at $90 \mathrm{~min}$ was again used to analyze between-group differences.

Analysis of variance of these data yielded a significant overall $F[F(3,14)=23.26, p<.05]$. The mean intakes by Groups E1, E2, and $\mathrm{C} 1$ were each compared with the mean intake by Group C2. Each comparison was significant $[\mathrm{Fs}(1,14)=49.03,9.91$, and 53.57, respectively, ps <.05], indicating that Groups $\mathrm{E} 1, \mathrm{E2}$, and $\mathrm{C} 1$ all drank significantly less $\mathrm{LiCl}$ than Group C2. Group C2 had had no previous experience with $\mathrm{LiCl}$, while Groups E1, E2, and $\mathrm{C} 1$ all experienced $\mathrm{LiCl}$ poisoning 4 days earlier. Thus, Groups $\mathrm{E} 1, \mathrm{E} 2$, and $\mathrm{C} 1$ all displayed a significant aversion to $\mathrm{LiCl}$. An additional comparison between the mean intakes by Groups E1 and E2 indicated that Group E2 drank significantly more $\mathrm{LiCl}$ than Group E1 $[F(1,14)=8.5, p<.05]$. Therefore, al- 


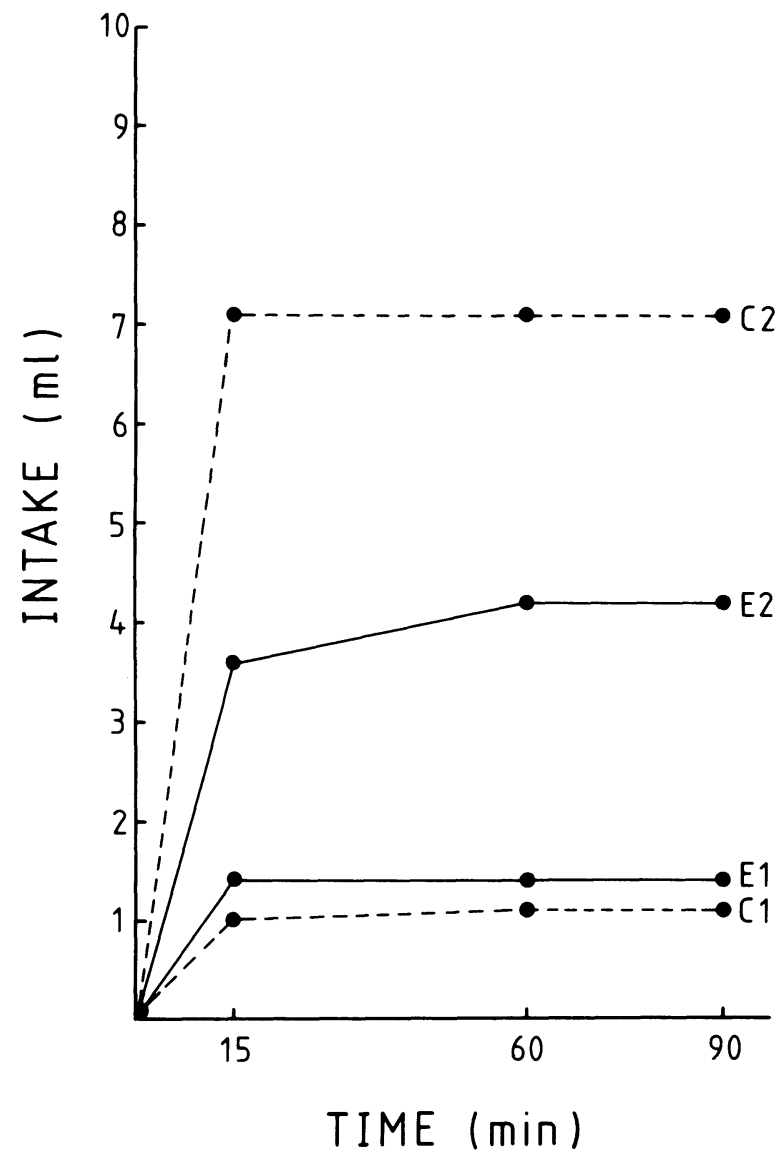

Figure 5. Mean LiCl intake by Groups E1, E2, C1, and C2 after 15,60 , and 90 min of fluid availability on Day 20.

though Groups E1 and E2 each displayed a significant aversion to $\mathrm{LiCl}$, the aversion displayed by Group E2 was less intense.

The mean $\mathrm{NaCl}$ intakes by all five groups after 15, 60 , and 90 min of availability on Day 24 are shown in Figure 6. The mean intakes by Groups E1, E2, and $\mathrm{C} 2$ were each similar to the mean intake by Group C3. The mean intake by Group C1 was much less. Intake at $90 \mathrm{~min}$ was again used to analyze between-groups differences, and analysis of variance of these data also yielded a significant overall $F$ $[F(4,18)=16.98, p<.05]$. The mean intakes by Groups E1, E2, C1, and C2 were each compared with the mean intake by Group C3. The comparison between groups $\mathrm{Cl}$ and $\mathrm{C} 3$ was significant $[F(1,18)$ $=50.28, \mathrm{p}<.05]$, indicating that Group C1 drank significantly less $\mathrm{NaCl}$ than Group $\mathrm{C3}$. As Group C3 had had no previous experience with $\mathrm{LiCl}$ while Group $\mathrm{Cl}$ had experienced $\mathrm{LiCl}$ poisoning on two previous occasions, this shows a significant generalized aversion to $\mathrm{NaCl}$ by Group $\mathrm{Cl}$ as well as its previously shown primary aversion to $\mathrm{LiCl}$. In contrast, comparisons between Groups E1 and C3, Groups E2 and C3, and Groups C2 and C3 were not significant. Groups E1 and E2 had both experienced
LiCl poisoning on two previous occasions, but neither displayed a significant generalized aversion to $\mathrm{NaCl}$ despite the fact that both had previously displayed primary aversions to $\mathrm{LiCl}$. Group $\mathrm{C} 2 \mathrm{had}$ experienced $\mathrm{LiCl}$ poisoning on one previous occasion, but did not display a significant generalized aversion to $\mathrm{NaCl}$ as was to be expected since, on this one occasion, the animals were allowed to consume $\mathrm{LiCl}$ but did not receive supplementary injections. An additional comparison between the mean intakes by Groups E1 and E2 was not significant, indicating that, in contrast to the primary aversions, the generalized aversions displayed by these two groups did not differ in intensity.

Once again, these results parallel those reported by Ralph and Balagura (1974). The control for electrode implantation (Group C1) displayed a primary aversion to $\mathrm{LiCl}$ and a generalized aversion to $\mathrm{NaCl}$. In contrast, both experimental groups (Groups E1 and E2) displayed a primary aversion to $\mathrm{LiCl}$ but did not generalize this aversion to $\mathrm{NaCl}$. Electrode implantation alone was again found to be sufficient to disrupt the generalized aversion to $\mathrm{NaCl}$ while

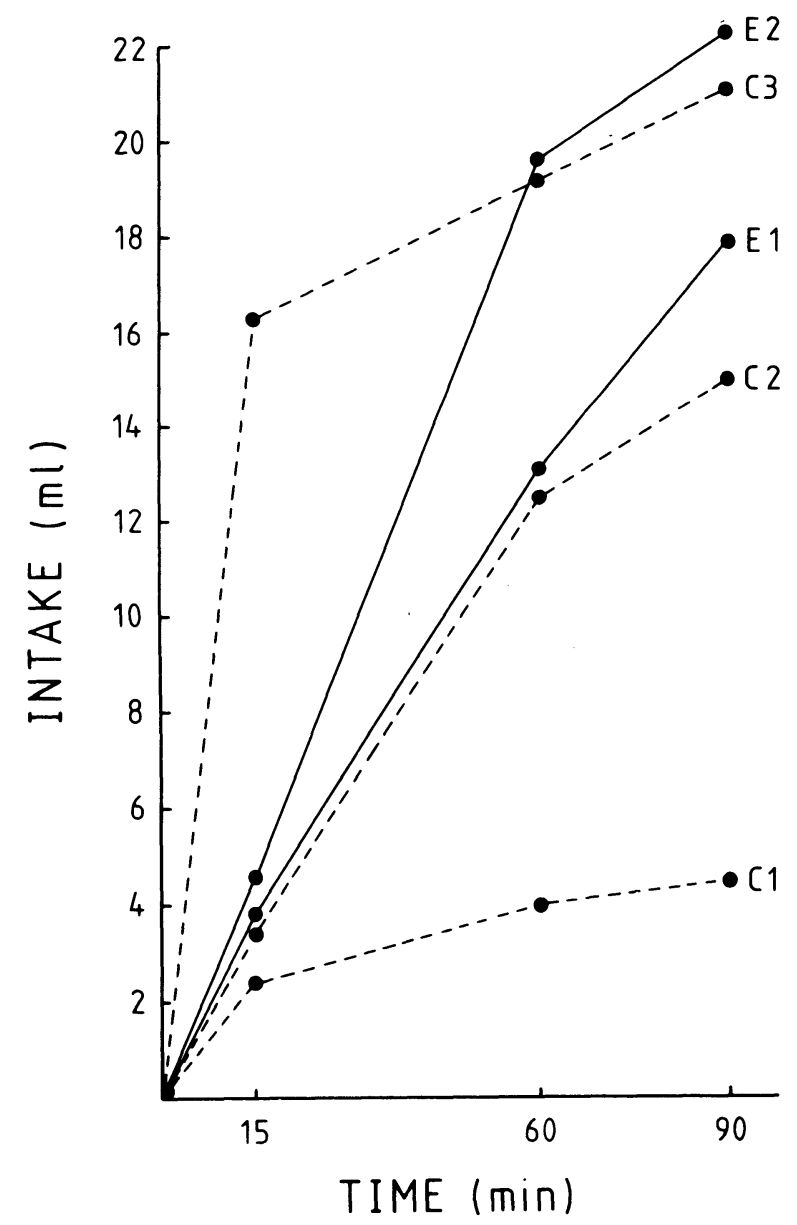

Figure 6. Mean $\mathrm{NaCl}$ intake by all groups after 15, 60, and 90 min of fluid avallability on Day 24. 
leaving intact the primary aversion to $\mathrm{LiCl}$. There was no evidence from the three animals in Group E2 that electrical stimulation at the parameters used here added materially to the effects of implantation with regards to $\mathrm{NaCl}$ intakes. However, it was found that this stimulation did have additional effects upon $\mathrm{LiCl}$ intakes, such that Group E2 displayed a less intense, although nevertheless intact, primary aversion.

The mean $\mathrm{NaCl}$ intake by Group E1 $(17.9 \mathrm{ml})$ was similar to that by Group E1 in Experiment 1 $(19.5 \mathrm{ml})$. Therefore, the severity of the deprivation schedule in Experiment 1 was probably not responsible for Groups E1's lower $\mathrm{NaCl}$ consumption in comparison with Ralph and Balagura's (1974) stimulated animals. The animals used in the study by Ralph and Balagura (1974) ranged in weight from 400 to $450 \mathrm{~g}$, which is considerably heavier than those used in Experiment 1 . This is a plausible remaining explanation of the greater $\mathrm{NaCl}$ intake by Ralph and Balagura's (1974) animals.

\section{EXPERIMENT 3}

The results of Experiments 1 and 2 are difficult to interpret in terms of neural mechanisms of tasteaversion learning. Although rats have difficulty discriminating between $\mathrm{LiCl}$ and $\mathrm{NaCl}$, those animals with electrodes implanted in the $\mathrm{LH}$ displayed a primary aversion to $\mathrm{LiCl}$ but did not generalize this aversion to $\mathrm{NaCl}$.

After observing the same effect subsequent to stimulation of the LH, Ralph and Balagura (1974) suggested that stimulation selectively disrupts some "generalization mechanism" within the brain or enhances the rat's ability to discriminate between $\mathrm{LiCl}$ and $\mathrm{NaCl}$. Both suggestions are concerned with explaining how stimulation could lead directly to behavioral discrimination between $\mathrm{LiCl}$ and $\mathrm{NaCl}$. The underlying cause, however, need not be so complex, because the potential for this discrimination is inherent in the experimental procedure. For example, if tissue damage caused by electrode implantation in the $\mathrm{LH}$ resulted in increased motivation to consume both substances, observable effects upon $\mathrm{LiCl}$ intake would be expected to be smaller due to its toxicity. That is, because onset of illness following $\mathrm{LiCl}$ consumption is rapid, increased motivation to consume this substance would not necessarily result in a dramatic increase in intake, since an aversion would be quickly reinforced. In contrast, $\mathrm{NaCl}$ intake would not be limited in this manner. Therefore, behavioral discrimination of $\mathrm{LiCl}$ and $\mathrm{NaCl}$ could be induced indirectly, by increasing motivation to consume both substances.

One way implantation of electrodes in the $\mathrm{LH}$ could increase motivation to consume $\mathrm{LiCl}$ and $\mathrm{NaCl}$ is by increasing thirst in general. Another is by increasing drive for sodium. Rats have an innate ap- petite for sodium, and deficient animals display an increased preference for salty solutions (Epstein \& Stellar, 1955; Richter, 1936). That drive for sodium could interact with a $\mathrm{LiCl}$ aversion as suggested is evident from a study which investigated the effects of increased drive induced by adrenalectomy. It was found that while control-operated animals exposed to $\mathrm{LiCl}$ consistently avoided $\mathrm{NaCl}$, adrenalectomized animals did not (Frumkin, 1971). The integrity of the primary aversion to $\mathrm{LiCl}$ was, however, not investigated.

In the following experiment, the possibility that implantation of electrodes in the $\mathrm{LH}$ has either of these effects was tested.

\section{Method}

Subjects. The subjects were 15 experimentally naive male rats, ranging in weight from 250 to $300 \mathrm{~g}$, supplied from the Wistarderived colony maintained at the University of Western Australia. All rats were housed under conditions identical to those in Experiment 1 .

General procedure. Each rat was allocated nonsystematically to an experimental group of 10 animals (Group E) or a control group of 5 animals (Group C).

Presurgical $\mathrm{NaCl}$ preference of each animal was measured for 10 consecutive days. Two weeks later, the animals in Group $\mathrm{E}$ were implanted with electrodes in the $\mathrm{LH}$ and animals in Group C underwent control surgery. After a recovery period of 20 days, postsurgical $\mathrm{NaCl}$ preference of each rat was measured for 10 consecutive days. On days when $\mathrm{NaCl}$ preferences were being measured, fluid availability was restricted to a 6 -h session beginning at 10:00 a.m. During these sessions, each rat was simultaneously offered two solutions in graduated drinking tubes. One tube contained distilled water and the other a $1.5 \% \mathrm{NaCl}$ solution. The relative positions of the two tubes was reversed across days. At the end of each session, intake of each fluid was recorded.

Surgical procedure. All animals were anesthetized by intraperitoneal injection of $1 \mathrm{ml} / \mathrm{kg}$ Pentathesin and placed in the stereotaxic apparatus. Anesthesia was maintained by respiration of ether (larger doses of Pentathesin were found to kill an unacceptably high proportion of experimental animals).

Animals in Group E were implanted with electrodes in the $\mathbf{L H}$, and animals in Group $C$ underwent control surgery as described in the Method section of Experiment 1. Electrodes were located by the set of coordinates which gave effective $\mathrm{LH}$ placements in Experiment 1.

Histological procedure. Animals in Group E were anesthetized deeply with an overdose of Pentathesin. Sections through the hypothalamus were prepared and electrode placements were determined as described in the Method section of Experiment 1.

\section{Results and Discussion}

Of the 15 animals, all but 1 from Group E survived the surgery.

Histological. All animals in Group E were found to have electrodes well placed in the $\mathrm{LH}$.

Behavioral. $\mathrm{NaCl}$ intakes by each animal on days when preference was being measured were expressed as a proportion of total intake. Mean presurgical and postsurgical proportional $\mathrm{NaCl}$ intakes by each animal were calculated, and group means are shown in Figure 7. Group $\mathrm{C}$ displayed a slight increase in mean proportional $\mathrm{NaCl}$ intake after surgery. Individual proportional increases in this group ranged 


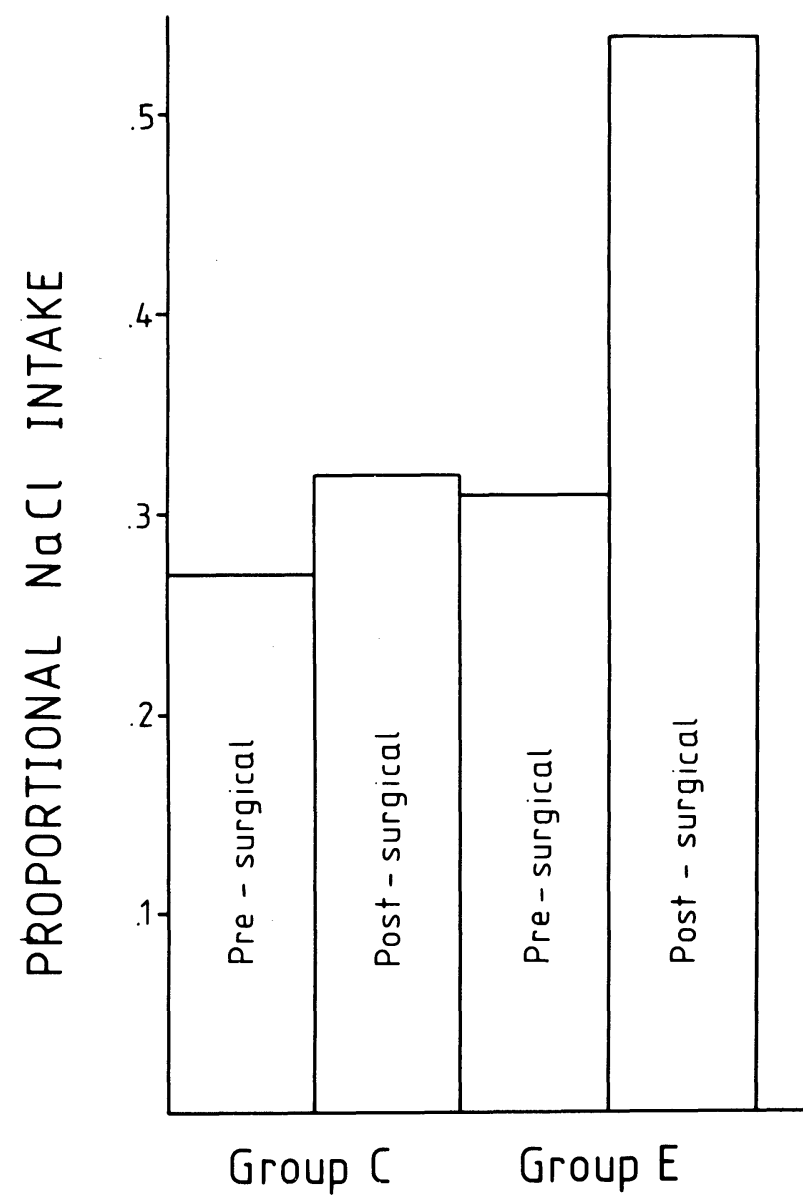

Figure 7. Mean presurgical and postsurgical proportional $\mathrm{NaCl}$ intakes by each group.

from .00 to .16. Group E showed a larger increase in proportional $\mathrm{NaCl}$ intake. Individual changes in this group ranged from -.02 to .58 . A number of animals in Group $\mathrm{E}$ increased their proportional $\mathrm{NaCl}$ intake markedly. Analysis of covariance of these data, using mean postsurgical proportional $\mathrm{NaCl}$ intake as criteria and mean presurgical proportional $\mathrm{NaCl}$ intakes as covariates, yielded a significant effect of groups $[F(1,11)=6.52, p<.05]$, indicating that mean postsurgical proportional $\mathrm{NaCl}$ intakes were not equal after allowing for variation in presurgical proportional $\mathrm{NaCl}$ intakes. Implantation of electrodes in the $\mathrm{LH}$ increased $\mathrm{NaCl}$ preference more than control surgery.

Mean daily combined intakes of $\mathrm{NaCl}$ and water by each animal were calculated, and the group means for the presurgical and postsurgical phases are shown in Figure 8. Group $C$ displayed a slight increase in total fluid intake after surgery. Individual increases in fluid intake ranged from .1 to $7.1 \mathrm{ml}$. Group E displayed a slightly larger increase. Individual changes in fluid intake ranged from -4.7 to $+21.7 \mathrm{ml}$. The slightly larger mean increase of
Group E was attributable mostly to marked increases by two animals that also showed marked increases in proportional $\mathrm{NaCl}$ intake. However, a number of other animals that showed similar increases in proportional $\mathrm{NaCl}$ intake showed little change in total fluid intake.

Analysis of covariance of these data, using mean postsurgical intakes as criteria and mean presurgical intakes as covariates resulted in an insignificant main effect of groups. There was no evidence that implantation of electrodes in the $\mathrm{LH}$ increased total fluid intake more than control surgery. This suggests that the increased proportional $\mathrm{NaCl}$ intake displayed by Group E was made up of an increased total $\mathrm{NaCl}$ intake and a compensatory lower water intake in most animals. A similar pattern has been observed in animals made sodium deficient by adrenalectomy (Richter, 1936).

The increased $\mathrm{NaCl}$ preference shown by Group $\mathrm{E}$ animals could be due to increased drive for sodium. An alternative interpretation is that it reflects poorer discrimination by these animals. While these two interpretations appear equally likely on the basis of this experiment, data from Experiments 1 and 2 favor the first. In both of these earlier experiments, electrodeimplanted animals responded differentially to offers of $\mathrm{NaCl}$ and tap water. When offered $\mathrm{NaCl}$, im-

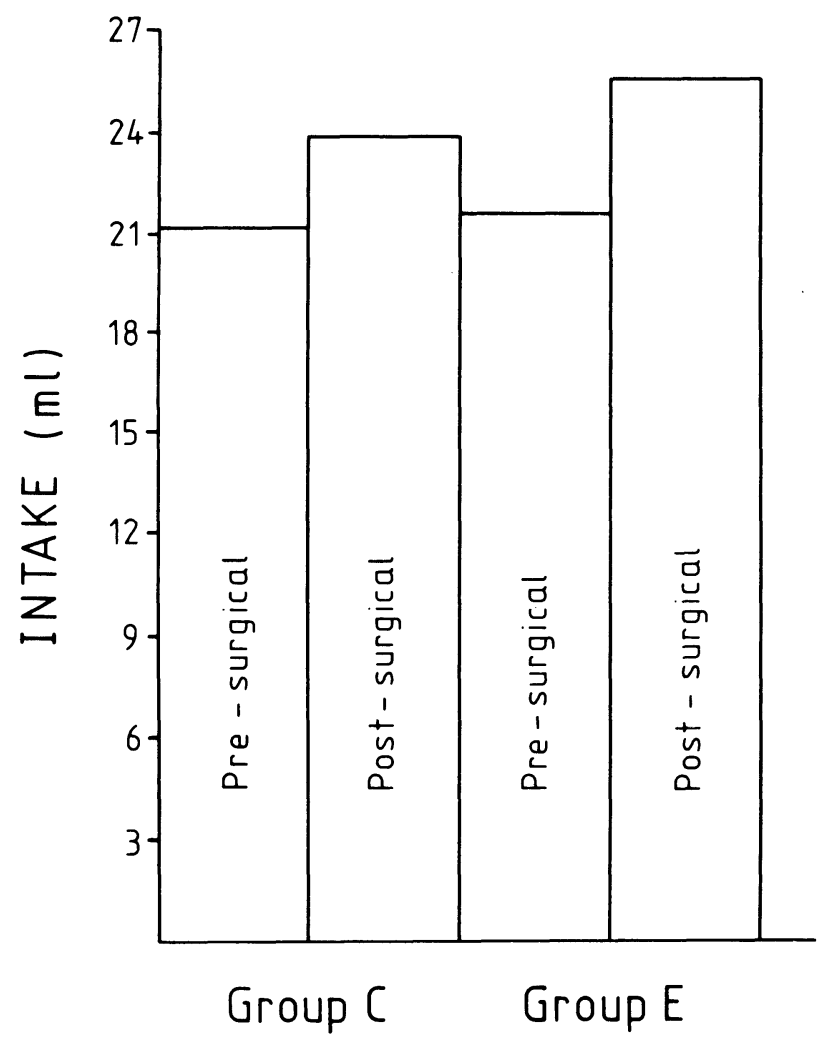

Figure 8. Mean presurgical and postsurgical dally combined intakes of $\mathrm{NaCl}$ and water by each group. 
planted animals displayed an initial reluctance to drink. This was reflected in the markedly lower 15 min $\mathrm{NaCl}$ consumption by these animals as compared with the LiCl-naive controls (e.g., Figure 3, Groups E1 and C3). In contrast, when offered tap water on days intervening $\mathrm{LiCl}$ and $\mathrm{NaCl}$ offers, electrode-implanted animals showed no hesitancy while drinking. This indicates that animals with electrodes implanted in the $\mathrm{LH}$ can discriminate $\mathrm{NaCl}$ and water.

The suggestion that electrode implantation may increase drive for sodium is further supported by the fact that one of several structures which could be expected to be damaged during lateral hypothalamic implantation, the LH itself, has been consistently implicated in neural control of sodium balance. Lesions in the $\mathrm{LH}$ have been reported to increase drive for sodium (Saad, Antunes-Rodrigues, Gentil, \& Covian, 1972) and to decrease response to procedures that increase sodium drive in normal rats (peritoneal dialysis, Wolfe, 1967; adrenalectomy, Wolf \& Quartermain, 1967; injection of mineralocorticoides, Schulkin \& Ruger, 1980, and Wolf, 1964). Cholinergic stimulation of the LH by infusion of carbachol through implanted cannulae has been found to increase sodium excretion in the urine (Franci, Silva-Netto, Saad, Camargo, \& Antunes-Rodrigues, 1980).

\section{GENERAL DISCUSSION}

The finding in Experiments 1 and 2 that electrode implantation in the $\mathrm{LH}$ disrupted a generalized aversion to $\mathrm{NaCl}$ while leaving a primary aversion to $\mathrm{LiCl}$ intact suggests that the similar effect observed by Balagura et al. (1972) and Ralph and Balagura (1974) subsequent to stimulation of the LH may also have been a consequence of electrode implantation. That the only additional effect of electrical stimulation was to reduce the intensity of the primary aversion to $\mathrm{LiCl}$ supports this contention. At least, electrode implantation itself is sufficient to interfere with expression of a generalized aversion to $\mathrm{NaCl}$ following $\mathrm{LiCl}$ poisoning.

The finding that implantation of electrodes in the LH increased sodium preference suggests that disruption of the generalized aversion in Experiments 1 and 2 was mediated by increased drive for sodium. As mentioned earlier, an increased drive for sodium induced by adrenalectomy has been shown to override a generalized aversion to $\mathrm{NaCl}$ (Frumkin, 1971).

Together, these interpretations imply that the effects observed by Balagura et al. (1972) and Ralph and Balagura (1974), as well as those seen in Experiments 1 and 2 of this study, were not a result of interference with associative processes underlying taste-aversion learning. Rather, taste avoidance, the performance measure from which taste-aversion learning is inferred, was disrupted by increased drive for sodium induced by electrode implantation.

Other studies, however, have indicated that the LH may be involved more directly in taste-aversion learning. As mentioned earlier, Lett and Harley (1974) have reported that animals allowed to self-stimulate the $\mathrm{LH}$ following pairing of the taste of decaffeinated coffee and injection of $\mathrm{LiCl}$ showed attenuated subsequent avoidance of coffee. Furthermore, Roth, Schwartz, and Teitelbaum (1973) and Schwartz and Teitelbaum (1974) found that animals with large lesions in the LH could not acquire a taste aversion. As these studies did not employ the $\mathrm{LiCl}-\mathrm{NaCl}$ tasteaversion procedure, their results cannot be explained in terms of motivation to consume sodium.

\section{General Implications}

The results reported here have two implications broader than those previously considered. The first concerns the suitability of the $\mathrm{LiCl}-\mathrm{NaCl}$ tasteaversion procedure for investigating the neural basis of taste-aversion learning. Due to the possibility of interaction between taste avoidance and sodium drive, this procedure is not ideal.

The second general implication relates to studies involving electrical stimulation of the brain through implanted electrodes. The results of this study reinforce the point made by Wyss and Goldstein (1976), who also found that electrode implantation induced significant behavioral effects. As they pointed out, analysis of behavior observed during or subsequent to stimulation must consider the fact that such stimulation is being administered to a brain-damaged animal. On the assumption that the effects of electrode implantation and stimulation will be additive, those of electrode implantation could be controlled for by comparing the behavior of stimlulated animals with that of animals only implanted with electrodes. If this assumption were incorrect and the effects were interactive, even this control would be inadequate. There is, however, no ready solution to this problem.

\section{REFERENCES}

Balagura, S., Ralph, T. L., \& Gold, R. Effect of electrical stimulation of diencephalic and mesencephalic structures on the generalized $\mathrm{NaCl}$ aversion after $\mathrm{LiCl}$ poisoning. Physiologist, 1972, 15, 77.

Draper, D., \& Venator, E. Chronic attachment of a connector to a rat's skull without screws. Physiology \& Behavior, 1972, 9, 113.

Epstein, A. N., \& Stellar, E. The control of salt preference in the adrenalectomized rat. Journal of Comparative and Physiological Psychology, 1955, 48, 167-172.

Franci, C., Silva-Netto, C., Saad, W., Camargo, L., \& ANTUNES-Rodrigues, J. Interaction between lateral hypothalamic area and the medial septal area in the control of sodium and potassium excretion in rats. Physiology \& Behavior, 1980, 25, 801-806. 
Frumkin, K. Interaction of $\mathrm{LiCl}$ aversion and sodium-specific hunger in the adrenalectomized rat. Journal of Comparative and Physiological Psychology, 1971, 75, 32-40.

GASton, K. E. Brain mechanisms of conditioned taste aversion learning: A review of the literature. Physiological Psychology, 1978, 6, 340-353.

LETT, B., \& HARLEY, C. Stimulation of lateral hypothalamus during sickness attenuates learned flavor aversions. Physiology \& Behavior, 1974, 12, 79-83.

Lindman, H. R. Analysis of variance in complex experimental designs. San Francisco: Freeman, 1974.

Nachman, M. Learned aversion to the taste of lithium chloride and generalization to other salts. Journal of Comparative and Physiological Psychology, 1963, 56, 343-349.

Pellegrino, L., Pellegrino, A., \& Cushman, A. A stereotaxic atlas of the rat brain. New York: Plenum, 1979.

RalPH, T., \& Balagura, S. Effect of intracranial electrical stimulation on the primary learned aversion to $\mathrm{LiCl}$ and the generalized aversion to $\mathrm{NaCl}$. Journal of Comparative and Physiological Psychology, 1974, 86, 664-669.

Richter, C. P. Increased salt appetite in adrenalectomized rats. Journal of Physiology, 1936, 115, 155-161.

Richter, C. P. Experimentally produced behavior reaction to food poisoning in wild and domesticated rats. Annals of the New York Academy of Sciences, 1953, 56, 225-239.

Roth, S., Schwartz, M., \& Teitelbaum, P. Failure of re- covered lateral hypothalamic rats to learn specific food aversions. Journal of Comparative and Physiological Psychology, 1973, 83, 184-197.

SaAd, W., Antunes-Rodrigues, J., Gentil, C., \& Covian, M. Interaction between hypothalamus, amygdala, and septal area in the control of sodium chloride intake. Physiology \& Behavior, 1972, 9, 629-636.

SChUlKIN, J., \& RUGer, J. Relation between lateral hypothalamic damage and impairment of sodium appetite: Evidence of subcortical mass action. Behavioral and Neurological Biology, 1980, 30, 90-96.

Schwartz, M., \& Teitelbaum, P. Dissociation between learning and remembering in rats with lesions in the lateral hypothalamus. Journal of Comparative and Physiological Psychology, 1974, 87, 394-398.

WoLf, G. Sodium appetite elicited by aldosterone. Psychonomic Science, 1964, 1, 211-212.

Wolf, G., \& Quartermain, D. Sodium chloride intake of adrenalectomized rats with lateral hypothalamic lesions. American Journal of Physiology, 1967, 212, 113-118.

Wyss, J. M., \& Goldste in, R. Lesion artifact in brain stimulation experiments. Physiology \& Behavior, 1976, 16, 387-389.

(Manuscript received April 12, 1982;

revision accepted for publication February 8, 1983.) 